\title{
A Quick Pre-Deployment Fibre Optic Link Design Methodology based on Q-factor in a Digital Eye
}

\author{
James Ntaganda \\ Electronic Department \\ Konkuk University \\ Seoul, Korea
}

\begin{abstract}
Fibre optic cables have become the main driving force behind high data throughput infrastructure. In modern wideband communication systems, they are deployed as backbone cables in many long haul links as well as links to clients (Fibre to home). Several Gigabits per second data rates have become common. Field engineers need to have a thorough knowledge of physics behind any physical component used to accomplish fibre optic cable deployment tasks.
\end{abstract}

To investigate different phenomena in such fibre optic links design, a $10 \mathrm{Km}$ repeaterless backbone link, arbitrarily between an onshore control station and an offshore configuration terminal, is designed. Design process is done based on specifications of products already on market. Power and bandwidth constraints are taken into account as major causes of errors upon signal reception. The link budget is done by combining different fibre optic link design approaches from a number of sources. Precise and summarised tables for quick power and bandwidth budgeting process are depicted. Design simulation is done by Optisystem 8.0 simulation software, a product of optiwave Inc.

The relationship between Quality factor (Q-factor) and BER (Bit Error Rates), their implications on received signal and how both are affected by different physical phenomena in optical communication systems is illustrated. Finally, quick design tables are drawn and graphs for design safety margin that conforms to ITU recommendations are plotted. The same tables can be extended and or modified to be customised to designer's target.

\section{Keywords}

Band width budget, Power Budget, Fibre optic Cable Link, Optisystem, Eye Diagram, Q-factor

\section{INTRODUCTION}

Fibre optic cables have revolutionised data throughput. They can be used as a backbone cable, or in broadband access network to offer various high-speed services to the end-user such as internet, multimedia, tele-medicine and distant learning [1]. In terrestrial communications, Fibre to the home (FTTH) is an optical access network architecture that uses optical fibres to replace all or part of the metallic cables to the end-user [25]. In hazardous subsea environment, there is a need for deploying fault tolerant systems which can support expansion into ultra deep waters [13], [14]. Optic cables are far tolerant than electrical cables in a subsea environment. Fibre Optical sensors are being used in such systems and are directly addressed through optical fibre cables [13], [14]. Data produced by such sensors have to be brought directly to the platform or to shore for monitoring, control, processing and management [13], [14]. In subsea well engineering, systems, fibre optic link provides continuous, real-time data, flow line conditions and temperature status with no well intervention. They have facilitated engineering and management personnel in reservoir performance optimisation and well production at reduced operation costs [21]. Electrical based communication system in subsea features $9.6 \mathrm{kbits} / \mathrm{sec}$ while with fibre and modern technology it goes up to $2.5 \mathrm{Gigabit} / \mathrm{sec}[13],[14]$. Field engineers need to have a thorough knowledge of physics behind any physical component to accomplish fibre optic cable deployment tasks. Optimised back bone link design with a good bandwidth and power budget is crucial for negotiating good signal reception and resource wastage trade-off. The rest of this paper is organised as follows. Section 2 introduces data rates and distances in relation to submersible cables. Section 3 introduces components required for fibre optic link design. Section 4 illustrates the selected steps for a quick fibre optic link design. In section 5 , the designed link is simulated by Optisystem 8.0 and finally conclusion presented in section 6 .

\section{DATA RATES AND DISTANCES}

Fibre Optic communication systems not only offer reliable communication means but also Gigabit communication bandwidths, long haul links, reduced installation cost, small size, less weight, easy installation, highest immunity to EMI with no cross talk effects, electrical isolation, most secure transmission, less signal loss and Longer design life time[17]. ITU recommends $45 \mathrm{TV}$ channels with $100 \mathrm{GHz}$ channel spacing just in $1550 \mathrm{~nm}$ attenuation window [15] using DWDM (Dense Wave Division Multiplexing).Alcatel-Lucent submarine networks [12] provides some information about submersible cable length and data that can be accommodated.

Table 1. Data and Distances for subsea networks

\begin{tabular}{|l|l|}
\hline Length & Data Transmission \\
\hline Less than 100m & $\begin{array}{l}10 / 100 \text { BaseT Electrical Transmission } \\
\text { cables }\end{array}$ \\
\hline Less than 10km & $\begin{array}{l}10 / 100 \text { BaseT, optical 1GE optical, less } \\
\text { than 1MBit/s electrical }\end{array}$ \\
\hline $\begin{array}{l}\text { Less than 100km, } \\
\text { Coastal }\end{array}$ & $\begin{array}{l}10 / 100 \text { BaseT Optical, 1GE optical, } \\
9,600 \mathrm{Bit} / \mathrm{s} \text { electrical }\end{array}$ \\
\hline $\begin{array}{l}\text { Less Than 1000Km, } \\
\text { Regional }\end{array}$ & $2.5 / 10 \mathrm{Gbit} / \mathrm{s}$ optical SDH. \\
\hline
\end{tabular}

\section{FIBRE OPTIC COMMUNICATION SYSTEM}

Fibre optic communication system covers a wide range of components and subsystems depending on application, environment and designer's target. In the rest of this section each component featured in this paper for quick design approach is described. 


\subsection{Pre-transmission Data Processing}

Data may be generated from random or user defined sources and may be in a raw analogue or processed digital form [5]. While most signals in real world are analogue, most communication systems today are digital and analogue signals have to be converted to digital form in most of signal processing stages [5], a procedure that is not covered in this paper. Coding is required to convert signals in a suitable form for the transmission medium adopted. Non Return to Zero (NRZ) or its Inverse (NRZI), Return to Zero (RZ), Manchester, Bipolar and delay encoding schemes are common in digital communication .Fibre optic communications mostly deploy NRZ and RZ [17]. Output from NRZ/RZ sequence generators are modulating signals. They modulate an optical signal from Laser Diode (LD) or Light Emitting Diode (LED) indirectly or directly [17]. Indirect modulation requires modulators. Phase, frequency, Amplitude, Mach-Zehnder, $\mathrm{LiNb}$ Mach-Zehnder, dual port drive, single port drive and electro-absorption modulators are commonly used [6]. In Wave Division Multiplexing (WDM) environment, direct Modulation is convenient, thus chosen for the design in this paper. Optical sources are principally p-n junctions. Table 2 shows the common optical sources [7], [18].

Table 2. Common optical source material

\begin{tabular}{|l|l|l|}
\hline $\begin{array}{l}\text { Semiconductor material } \\
\text { used }\end{array}$ & $\begin{array}{l}\text { Band gap } \\
\text { Energy (eV) }\end{array}$ & $\begin{array}{l}\text { Central } \\
\text { Wavelength(nm) }\end{array}$ \\
\hline GaAsP & 1.88 & 660 \\
\hline GaAlAs & $1.38-1.55$ & $800-900$ \\
\hline GaAs & 1.33 & 930 \\
\hline InGaAsP & $0.95-0.80$ & $1330-1550$ \\
\hline
\end{tabular}

\subsubsection{Optical Source Selection Criteria}

On-field fibre optic link design Engineers design systems based on link requirement and specifications of products available on market. For an optical source, Central wavelength, spectral width, and output power and rise time are most important parameters [17]. LDs exhibit narrower spectral width, quicker response, higher power and operate at higher wavelengths with less attenuation [8], thus less coupling losses, high data rates. LDs are ideal for long haul fibre optic communications and Gigabit bitrates compared to LEDs [17], [18]. For the link length and data rates review [12], LDs are ideal for the design presented in this paper.

\subsection{Fibre Optic Cable}

Fibre optic cable is basically an optical signal waveguide in which optical signal transmission is governed by total internal reflection and Snell's law [9]. Fibre optic cables are designed to have an inner core, with high refractive index, denoted as $\left(\eta_{1}\right)$ and the outer cladding with a less refractive index $\left(\eta_{2}\right)$. If the angle of incidence $\Phi_{1}$ is increased, the associated angle of refraction $\Phi_{2}$ also increases [9].

If $\Phi_{1}$ is further increased and $\Phi_{2}=90^{\circ}$, then light appears neither in the cladding nor in the core. Angle $\Phi_{1}$ at this point is called critical angle $\left(\Phi_{c}\right)$ and the refracted ray grazes the interface. When $\Phi_{1}$ is slightly increased further, the refracted ray appears in the core medium and light is confined within the core and guided along the fibre cable. Angle Фc depends on the fibre cable material(s) used. All physics phenomena at core-glass cladding is governed by Snell's law in equation (1)

$\eta_{1} \sin \left(\varphi_{1}\right)=\eta_{2} \sin \left(\phi_{2}\right), \frac{\sin \left(\phi_{1}\right)}{\sin \left(\phi_{2}\right)}=\frac{\eta_{2}}{\eta_{1}}$
If the refraction angle is considered $90^{\circ}$, then $\mathrm{Eq}(2)$ follows.

$$
\frac{\sin \left(\phi_{1}\right)}{\sin \left(90^{0}\right)}=\frac{\eta_{2}}{\eta_{1}} ; \sin \left(\phi_{\mathrm{c}}\right)=\frac{\eta_{2}}{\eta_{1}} ; \cos \left(\phi_{\mathrm{c}}\right)=\frac{\sqrt{\eta_{1}^{2}-\eta_{2}^{2}}}{\eta_{1}}=\sin \left(\phi_{\mathrm{c}}\right)
$$

If the same principle is applied at the core-air interface, then equation (2) is re-arranged into equation (3).

$$
\mathrm{n}_{\mathrm{a}} \sin \left(\phi_{\mathrm{a}}\right)=\eta_{1} \sin \left(\phi_{\mathrm{c}}\right)=\eta_{1} \frac{\sqrt{\mathrm{n}_{1}^{2}-\mathrm{n}_{2}^{2}}}{\mathrm{n}_{1}}=\sqrt{\mathrm{n}_{1}{ }^{2}-\mathrm{n}_{2}{ }^{2}}
$$

But it is known that $\eta_{\mathrm{a}}=1$, for air around the fibre end where the optical signal is launched, hence Equation (4) holds.

$$
\sqrt{\mathrm{n}_{1}^{2}-\mathrm{n}_{2}^{2}}=\sin \left(\mathrm{n}_{\mathrm{a}}\right)=\mathrm{NA}
$$

This is called Numerical Aperture (NA).It is quoted by manufacturers of fibre optic cables [15]. The beam from an optical source has to be confined within this conical angle, called acceptance angle [15], [17]. This explains why LEDs have more coupling loses than LDs because they have wider spectral width.

\subsubsection{Fibre optic cables for communication}

Communication optic fibre cables are classified as single mode or multimode depending on the size of this core [16], [17]. Single mode has a very thin core to allow only one modal ray whereas multimode has wider core to allow more than one mode [15]. The number of modes travelling along the optic fibre is given by equation (5).

$\mathrm{M}=0.5 \mathrm{~F}^{2} ; \quad \mathrm{F}=\frac{\mathrm{d} \cdot \pi \cdot \mathrm{NA}}{\lambda}$

Where $\mathrm{d}$ is the cable diameter, $\mathrm{F}$ is normalised frequency; $\lambda$ is the source wavelength and NA is the Numerical aperture stated in equation (4).

\subsubsection{Fibre optic cables and transmission modes}

Optical communications system designers select cables according to the application envisaged and the environment in which it will be deployed. The major parameters focused on are but not limited to Attenuation, desperation and bandwidth .Figure 1 shows these operation windows [8]. Dispersion can also be classified as modal or material as described in Equations (6) and (7) respectively. Bandwidth is the most desirable parameter in any communication system. Suppliers indicate it as $3 \mathrm{~dB}$ bandwidth [18]. Band width (BW) is related to rise time (Tr), dispersion (D) and data rates(R). The relation depends on the fibre cable length (L) as depicted in equations 8 and 9 for mono-mode and multimode fibre optic cables respectively.

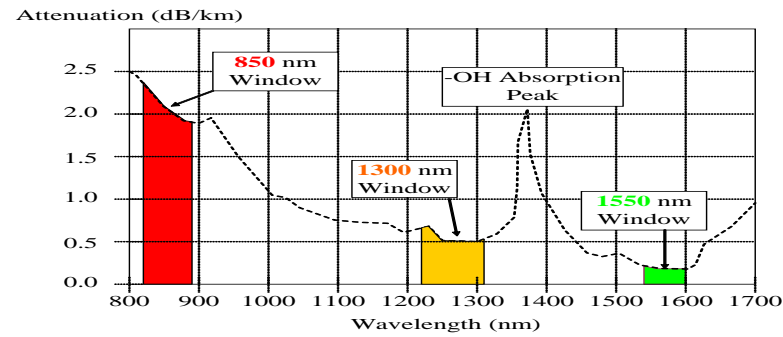

Figure 1: Fibre optic cable attenuation windows.

The magnitude of modal dispersion is obtained practically by measurement using modern optical meters, data sheet or theoretically estimated by Mathematical equation (6). 
$\frac{\Delta \mathrm{T}_{\text {modal }}}{\mathrm{L}}=\frac{\eta_{1}}{\mathrm{c}}\left[\frac{\mathrm{n}_{1}}{\mathrm{n}_{2}}-1\right]$

Where $\left(\Delta \mathrm{T}_{\text {modal }} / \mathrm{L}\right)$ is the modal dispersion per Kilometer cable length, $c$ is the speed of light; $n_{1}$ and $n_{2}$ are refractive indices of core and cladding respectively. It gives the time dispersion for a given unit distance and normally expressed in picoseconds/Km [17]

Material dispersion per kilometer-cable length $\left(\Delta \mathrm{T}_{\text {material }} / \mathrm{L}\right)$ is given by;

$$
\frac{\Delta \mathrm{T}_{\text {material }}}{\mathrm{L}}=\frac{\Delta \lambda}{\mathrm{c}} *\left|\mathrm{Y}_{\mathrm{m}}\right|
$$

Where $\Delta \lambda$ is the spectral width, $\lambda$ is the central wavelength, c is the speed of light and $\mathrm{Y}_{\mathrm{m}}$ is the material dispersion coefficient. For a monomode fibre, bandwidth is given in equation (8) and step index multimode fibre bandwidth is given in equation (9). For a given bandwidth $(B W)$, the data $\operatorname{rate}(R)$ for any cable is given by equation (10), where $t$ is the time dispersion, for a NRZ signal [17],[18].

$$
\begin{aligned}
& \mathrm{BW}=\frac{1}{\mathrm{D} \cdot \Delta \lambda \cdot \mathrm{L}(\mathrm{Km})} ; \mathrm{T}_{\mathrm{r}}=\frac{1}{2.86 \mathrm{BW}} ; \mathrm{T}_{\mathrm{r}}=\frac{\mathrm{D} \cdot \Delta \lambda \cdot \mathrm{L}(\mathrm{Km})}{2 \cdot 86} \\
& \mathrm{BW}=\frac{1}{2 \frac{\eta_{1}}{\mathrm{c}}\left(\frac{\eta_{1}}{\eta_{2}}-1\right) \cdot \mathrm{L}(\mathrm{Km})} ; \text { and, } \mathrm{T}_{\mathrm{r}}=\frac{2 \frac{\eta_{1}}{\mathrm{c}}\left(\frac{\eta_{1}}{\eta_{2}}-1\right) \cdot \mathrm{L}(\mathrm{Km})}{2.86}
\end{aligned}
$$

$\mathrm{R}=2 \mathrm{BW}=1 / \mathrm{t}$

\subsection{Connectors and splices}

Connectors join fibre cables of different sizes, repaired cables (joint connection) or connecting fibre cables to system components if demountable. To a system designer, the aim is to achieve less insertion loss for both connectors and splices which must also to be compatible with the system components. Splices and connectors with as low as $0.1 \mathrm{~dB}$ and $0.5 \mathrm{~dB}$ insertion losses respectively are available.

\subsection{Optical Amplifiers}

Most optical amplifiers are classified as 1R (Regeneration), $2 \mathrm{R}$ (Regeneration and Reshaping) or 3R (RegenerationReshaping-Retiming/Retransmission) [17], [18], [25]. 1R amplifies the signal without changing the shape, $2 \mathrm{R}$ amplifies and limits the signal in its 0 s and $1 \mathrm{~s}$ levels and $3 \mathrm{R}$ is $2 \mathrm{R}$ with information Retiming. 3R principle involves in an intermediate optical-to-electrical signal conversion before retransmission, thus not recommended for subsea systems [13], [14]. The EDFA (Erbium Doped Fibre Amplifier) operates on $1 \mathrm{R}$ and $2 \mathrm{R}$ principles [17], [28], thus to be used in this paper to avoid EMI [17]. It is worth mentioning that EDFA is different from inter-cable regenerators.

\subsection{Multiplexers and De-multiplexers}

Radio engineers have been using Frequency Division Multiplexing (FDM) as a way of increasing the capacity of analogue radio signal transmissions. Similarly, fibre optic engineers combine distinct wavelengths (colors) to be transmitted over a single fibre cable, each of which representing a communication channel. This is termed as Wavelength Division Multiplexing (WDM) [27]. It is possible to fully utilise the transmission capacity of an optic fibre cable, now be considered to be in terabits per second. As demand for traffic increases, the spacing in terms of wavelength of these channels has been increasingly narrowed to accommodate more colors over a small wavelength range. This is termed a Course WDM (CWDM) or Dense WDM (DWDM) [27]. With EDFA, CWDM has become more reliable [17] and ITU-T recommends 45 TV channels in just $1550 \mathrm{~nm}$ window with spacing of $100 \mathrm{GHz}$ [15]. In this paper, an $8 \times 1-1 \times 8$ CWDM transceiver system [15], of 2.5Gbps per channel is designed.

\subsection{Optical Receivers}

The main component at the receiving end of an optical link is a photo detector. Parameters of interest are sensitivity, responsivity, quantum efficiency and Rise time [17]. Sensitivity is normally quoted in $\mathrm{dBm}$ and should be negatively lower than the power reaching the photo detector. Quantum Efficiency $(Q E)$ indicates the ratio of electron-hole (e-h) pairs released to the number of incident photons causing it [17], [18]. QE of $80 \%$ means that out of 100 incident photons, only 80 e-h pairs were released. Practically, it goes up to $90 \%$ but less than $100 \%$ due to fibre-detector coupling losses, light absorption by $\mathrm{p}$ or $\mathrm{n}$ region and detector leakage current). Responsivity is related to $\mathrm{QE}$, the ratio of output current to the input optical power $(\mathrm{A} / \mathrm{W})$ and varies with wavelength. $\mathrm{R}=\eta \lambda / 1240$ where, $\mathrm{R}$ is the detector responsivity, in Ampere per Watt $(\mathrm{A} / \mathrm{W}), \eta$ is the quantum efficiency (percentage) and $\lambda$ is the operation wavelength (nm). Response time gives both the rise and fall times and signifies how quick the detector is in converting optical power into electrical current. It should normally be shorter (quicker) than incoming signal to avoid loss of information. Apart from the photo detector, optical receiver incorporates other components like optical pre-amplifier, optical noise filter; post amplifier and electrical noise filter [17].

\section{METHODOLOGY}

The system design focused on both power and bandwidth budgets for an arbitrary optical transmitter (CWDM) on shore to a seabed node. Eight channels each with data rate of 2.5 Gigabit/sec, multiplexed over a Single Mode Fibre by CWDM, were designed to operate in $1550 \mathrm{~nm}$ attenuation window, to encounter less attenuation (figure 1). Only one of the eight channels formed a basis of the design in this paper and to ensure that all channels worked well, in simulations and results analysis, the channel with much reception errors is considered, implying that if it worked well, then other channels would have less reception errors

\subsection{Power and Bandwidth Budgets}

The aim power budget is to ensure that optical signal power reaching photo detector is negatively higher than the detector sensitivity [18]. On the other hand the principle behind bandwidth budget is to ensure that the system responds quicker than the data rates sent form respective sources. The easiest way for band width budget, to avoid mathematical arguments which may rise due to other existing methods and the rise time, is to find the square root of sums of squares of the individual component rise time [18].

$\mathrm{T}_{\text {sys }}=\sqrt[2]{\mathrm{T}_{\mathrm{s}}^{2}+\mathrm{T}_{\text {mux }}{ }^{2}+\mathrm{T}_{\mathrm{f}}{ }^{2}+\mathrm{T}_{\text {demux }}{ }^{2}+\mathrm{T}_{\mathrm{R}}{ }^{2}}$

Where,

$\mathrm{T}_{\text {sys }}$ is the entire system rise time, $\mathrm{T}_{\text {mux }}$ is the rise time of the multiplexer, $\mathrm{T}_{\mathrm{f}}$ is the fibre rise time, $\mathrm{T}_{\text {demux }}$ is the Demultiplexers rise time, $T_{s}$ is the source rise time and $T_{R}$ is the receiver rise time. $T_{\mathrm{s}}$ is normally quoted by manufacturers but in this case was calculated according to software expressions.

$\mathrm{T}_{\mathrm{S}}=\frac{1}{\mathrm{~K} * \text { bitrate }}$ 
$\mathrm{K}$ is constant that was varied to meet the required rise time. Fibre optic to be viewed as a low pass filter whose cut-off frequency should be higher than the highest frequency component of any signal with rise time $\left(\mathrm{T}_{\mathrm{sg}}\right)$ to pass through it, and this inequality (13) needs to hold, for minimum information losses.

$\mathrm{T}_{\mathrm{sys}} \leq 0$

In other words,

$\mathrm{T}_{\mathrm{sys}}(\mathrm{NRZ}) \leq 70 \%\left(\frac{1}{\text { Bitrate }}\right)=70 \%($ bitperiod $)$

And

$\mathrm{T}_{\mathrm{sys}}(\mathrm{RZ}) \leq 35 \%\left(\frac{1}{\text { Bitrate }}\right)=35 \%$ (bit period)

\subsection{Quick Design Tables}

Both power and bandwidth budgeting are presented and Tables 4 and 5. As prerequisite, the general system specifications are first identified. Table 3 shows the general system specifications suggested in this paper which can be extended or modified to be tailored to designer's goal.

Table 3. General system design requirements

\begin{tabular}{|c|c|c|c|c|}
\hline $\begin{array}{l}\mathrm{S} . \\
\mathrm{N}\end{array}$ & Parameter & value & Units & $\begin{array}{l}\text { Description and } \\
\text { comments }\end{array}$ \\
\hline 1 & Data rate & $8 \times 2.5$ & $\begin{array}{l}\text { Gigabit/se } \\
\text { c }\end{array}$ & $\begin{array}{l}\text { Maximum value, } \\
\text { CWDM link } \\
\text { capacity \& } \\
\text { SONET/SDH } \\
\text { compatible }\end{array}$ \\
\hline 2 & $\begin{array}{l}\text { Link } \\
\text { length }\end{array}$ & 100 & $\mathrm{Km}$ & $\begin{array}{l}\text { Maximum link } \\
\text { length- onshore } \\
\text { to sea } \\
\text { bed(arbitrary) }\end{array}$ \\
\hline 3 & Q-factor & $\begin{array}{l}6 \text { and } \\
\text { above }\end{array}$ & $\begin{array}{l}\text { amplitude } \\
\text { units(a.u) }\end{array}$ & $\begin{array}{l}\text { Minimum } \\
\text { corresponding to } \\
10^{-9} \mathrm{BER} \text { (ITU-T } \\
\text { Recommendation } \\
\text { ) }\end{array}$ \\
\hline 4 & $\begin{array}{l}\text { modulatio } \\
\mathrm{n}\end{array}$ & & - & $\begin{array}{l}\text { OOK(On-Off- } \\
\text { Keying) direct } \\
\text { with NRZ format }\end{array}$ \\
\hline \multirow[t]{2}{*}{5} & \multirow[t]{2}{*}{$\begin{array}{l}\text { Reference } \\
\text { Wave } \\
\text { length }\end{array}$} & $\begin{array}{l}1552.5 \\
2\end{array}$ & $\mathrm{~nm}$ & \multirow{2}{*}{$\begin{array}{l}\text { Located in } \\
1550 \mathrm{~nm} \\
\text { Attenuation } \\
\text { window }\end{array}$} \\
\hline & & (193.1) & $(\mathrm{THz})$ & \\
\hline
\end{tabular}

Table 4. Power budget summary

\begin{tabular}{|c|c|c|c|c|}
\hline S.N & Parameter & value & units & description \\
\hline 1 & $\begin{array}{l}\text { Power into } \\
\text { fibre }\end{array}$ & 30 & $\mathrm{dBm}$ & $\begin{array}{l}10 \mathrm{dBm}(\mathrm{TX})+20 \mathrm{~dB} \\
(\mathrm{EDFA}), \text { minimum values. }\end{array}$ \\
\hline 2 & $\begin{array}{l}\text { Receiver } \\
\text { sensitivity }\end{array}$ & -21 & $\mathrm{dBm}$ & $\begin{array}{l}\text {-18dBm improved by } 3 \mathrm{~dB} \\
\text { Preamplifier gain, } \\
\text { minimum value. }\end{array}$ \\
\hline 3 & $\begin{array}{l}\text { System } \\
\text { Gain }\end{array}$ & 51 & $\mathrm{dBm}$ & $\begin{array}{l}\text { power into fibre - Rx } \\
\text { sensitivity Step }\end{array}$ \\
\hline 4 & $\begin{array}{l}\text { System } \\
\text { Safety } \\
\text { margin or } \\
\text { (sometimes } \\
\text { called } \\
\text { penalty) }\end{array}$ & 11.7 & $\mathrm{~dB}$ & $\begin{array}{l}\text { Aging factor(dB)+ } \\
\text { Repair factor(+ } \\
\text { Environmental factor }(\mathrm{dB}) \\
\text { +dispersion factor(dB)+ } \\
\text { Jitter factor }(\mathrm{dB})+ \\
\text { Design error margin }(\mathrm{dB}) \text {. } \\
\text { *All known to planning } \\
\text { engineers. }\end{array}$ \\
\hline 5 & $\begin{array}{l}\text { Total } \\
\text { connector } \\
\text { losses }\end{array}$ & 2 & $\mathrm{~dB}$ & $\begin{array}{l}\text { Four connectors } x \text { 0.5dB } \\
\text { maximum(Wet-mate ) }\end{array}$ \\
\hline 6 & $\begin{array}{l}\text { Total } \\
\text { splice } \\
\text { losses }\end{array}$ & 0.4 & $\mathrm{~dB}$ & $\begin{array}{l}\text { Four splicesx } 0.1 \mathrm{~dB} \\
\text { maximum, for } 25.2 \mathrm{Km} \text { per } \\
\text { reel to make a total link of } \\
100 \mathrm{Km}\end{array}$ \\
\hline 7 & $\begin{array}{l}\text { Mux and } \\
\text { Demux } \\
\text { losses }\end{array}$ & 3 & $\mathrm{~dB}$ & $1.5 \mathrm{~dB}$ maximum each \\
\hline 8 & EDFA loss & 1.25 & $\mathrm{~dB}$ & $\begin{array}{l}\text { Maximum attenuation At } \\
\text { both } 980 \mathrm{~nm} \text { and } 1550 \mathrm{~nm} \text {, } \\
(0.1 \mathrm{~dB} \times 5 \mathrm{~m})+(0.15 \mathrm{dBx} 5 \mathrm{~m}) \\
\text { respectively for } 5 \mathrm{~m} \mathrm{EDFA}\end{array}$ \\
\hline 9 & $\begin{array}{l}\text { Total } \\
\text { losses } \\
\text { excluding } \\
\text { fibre cable }\end{array}$ & 6.65 & $\mathrm{~dB}$ & Adding steps $5,6,7$ and 8 \\
\hline 10 & $\begin{array}{l}\text { Link loss } \\
\text { budget }\end{array}$ & 39.3 & $\mathrm{~dB}$ & $\begin{array}{l}\text { Subtracting step } 4 \text { from } \\
\text { step } 3\end{array}$ \\
\hline 11 & $\begin{array}{l}\text { Maximum } \\
\text { allowable } \\
\text { cable } \\
\text { attenuation }\end{array}$ & 32.65 & $\mathrm{~dB}$ & $\begin{array}{l}\text { Subtracting step } 9 \text { from } \\
\text { step } 10\end{array}$ \\
\hline 12 & $\begin{array}{l}\text { Maximum } \\
\text { normalised } \\
\text { cable } \\
\text { attenuation }\end{array}$ & 0.3265 & $\mathrm{~dB} / \mathrm{Km}$ & $\begin{array}{l}\text { Step } 11 \text { divided by link } \\
\text { length }(100 \mathrm{Km}) \text {. }\end{array}$ \\
\hline 13 & $\begin{array}{l}\text { Fibre cable } \\
\text { attenuation } \\
\text { used }\end{array}$ & 0.25 & $\mathrm{~dB} / \mathrm{Km}$ & $\begin{array}{l}\text { Available on market and } \\
\text { Specified on datasheet }\end{array}$ \\
\hline 14 & $\begin{array}{l}\text { Total fibre } \\
\text { cable } \\
\text { attenuation }\end{array}$ & 25 & $\mathrm{~dB}$ & $\begin{array}{l}\text { Step } 13 * \text { link } \\
\text { length }(100 \mathrm{Km})\end{array}$ \\
\hline 16 & $\begin{array}{l}\text { Received } \\
\text { signal }\end{array}$ & -1.65 & $\mathrm{~dB}$ & $\begin{array}{l}\text { (Step 9+step14) subtracted } \\
\text { from step } 1\end{array}$ \\
\hline
\end{tabular}




\subsection{Bandwidth Budget}

The band width budget was accomplished by using equations in the description column (table 5) and the design requirement in table 3.

Table 5. Bandwidth budget

\begin{tabular}{|c|c|c|c|c|}
\hline S.N & parameter & value & units & description \\
\hline 1 & $\mathrm{~T}_{\text {source }}$ & 0.8 & $\mathrm{pS}$ & $\begin{array}{l}\text { Maximum source rise } \\
\text { time(per channel), } \\
\text { Obtained from equation (12) } \\
\text { with } \mathrm{K}=500 .\end{array}$ \\
\hline 2 & $\mathrm{~T}_{\operatorname{mux}}$ & 0.03 & $\mathrm{nS}$ & $\begin{array}{l}\text { Maximum multiplexer rise } \\
\text { time, Obtained from } \\
\text { equation (8), at } \mathrm{BW}=10 \mathrm{GHz} \text {. }\end{array}$ \\
\hline 3 & $\mathrm{~T}_{\text {fibre }}$ & 0.00012 & $\mathrm{pS}$ & $\begin{array}{l}\text { Maximum fibre rise time, } \\
\text { Obtained from equation }(8) \\
\text { with dispersion of } \\
16.75 \mathrm{ps} / \mathrm{nm} / \mathrm{km} \text { and spectral } \\
\text { width of } 0.018 \mathrm{um}\end{array}$ \\
\hline 4 & $\mathrm{~T}_{\text {demux }}$ & 0.03 & $\mathrm{nS}$ & $\begin{array}{l}\text { Maximum Demultiplexers } \\
\text { rise time , Obtained from } \\
\text { equation (8), at } \mathrm{BW}=10 \mathrm{GHz} \text {. }\end{array}$ \\
\hline 5 & $\mathrm{~T}_{\mathrm{Rx}}$ & 0.186 & $\mathrm{nS}$ & $\begin{array}{l}\text { Maximum receiver rise time, } \\
\text { Obtained from equation ( } 8 \text { ) } \\
\text { with } \mathrm{BW}=0.75 * \text { bitrates (low } \\
\text { pass). }\end{array}$ \\
\hline 6 & $\mathrm{~T}_{\text {sys }}$ & 0.8 & $\mathrm{pS}$ & $\begin{array}{l}\text { Maximum system rise time } \\
\text { Obtained from equation (11). }\end{array}$ \\
\hline 7 & $\mathrm{~T}_{\text {signal }}$ & 0.4 & $\mathrm{nS}$ & $\begin{array}{l}\text { Signal rise time Obtained } \\
\text { from ' } 1 / \text { bitrates' (NRZ } \\
\text { signal). }\end{array}$ \\
\hline 8 & $\begin{array}{l}\text { Required } \\
\mathrm{T}_{\text {sys }}\end{array}$ & $\begin{array}{l}<70 \% \\
\text { of Ts } \\
=0.28\end{array}$ & $\mathrm{nS}$ & $\begin{array}{l}\text { Maximum required system } \\
\text { rise time obtained from } \\
\text { Inequality (13), and satisfied } \\
\text { since } T_{\text {sys }}=0.8 \mathrm{ps}(\text { step } 6) \text {. }\end{array}$ \\
\hline
\end{tabular}

\section{SIMULATION RESULTS}

Spectrum analyzers, WDM analyzers, optical power meters, BER analyzers and eye diagram analyzers are used to visualize the link and channels performances. The BER analyser at the receiver incorporates BER patterns, numerical values of BER, threshold values, eye height, decision instant in the eye opening, Q-factor and eye diagrams. Optical power meter, spectrum analyzer and WDM analyzer are connected along the fibre right from the WDM transmitter output, MUX output, EDFA output, before and after WDM Demux to analyse signal attenuated along the optical cable link as well as the spectrum spreading.

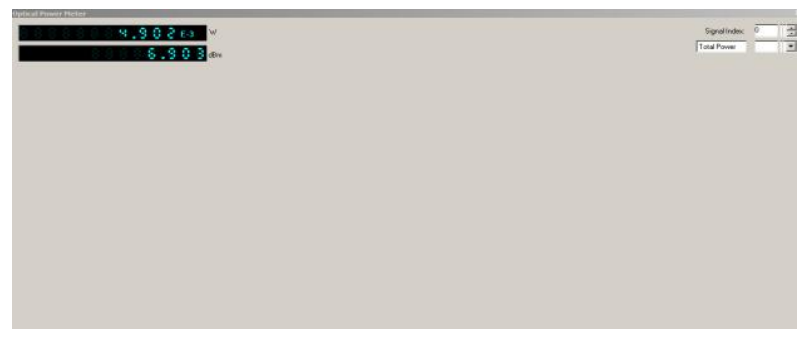

Figure 2: Optical power meter before amplification at multiplexer output (Average power is positive)

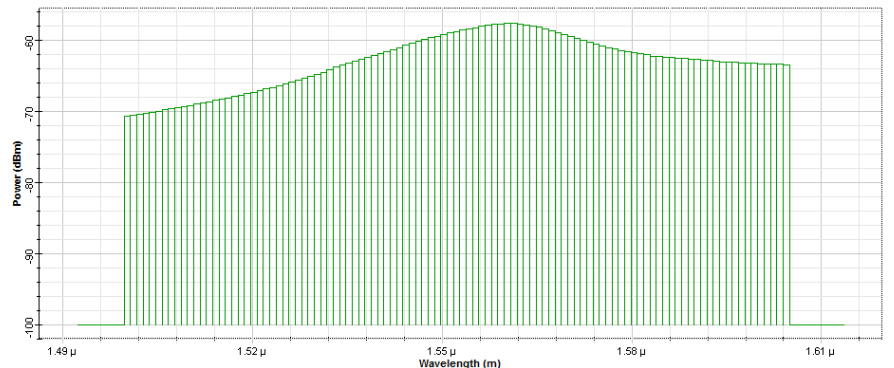

(a)Noise power

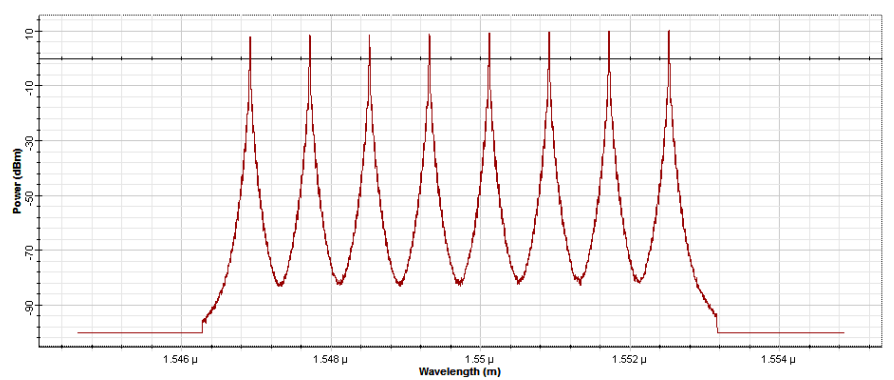

(b) Signal power

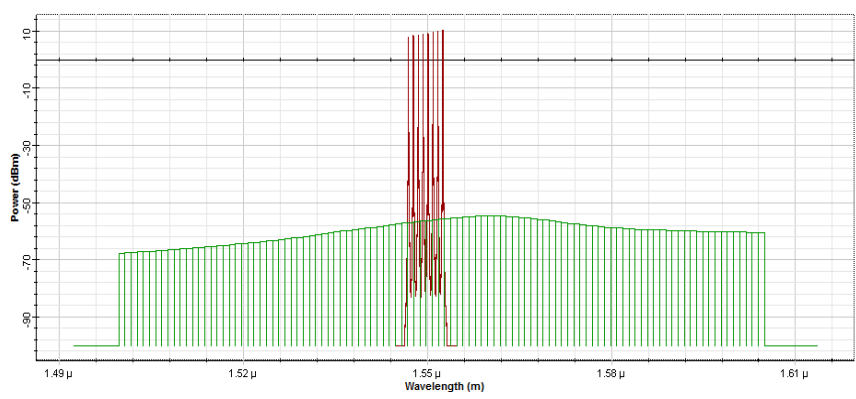

Figure 3: WDM channel spectral spreading before amplification at multiplexer output (power is positive compared to noise and no side bands).

\begin{tabular}{|l|l|l|l|}
\hline Frequency $(\mathrm{THz})$ & Signal Power $(\mathrm{dBm})$ & Noise Power $(\mathrm{dBm})$ & OSNR $(\mathrm{dB})$ \\
\hline 193.1 & 5.3460662 & -72.812439 & 78.158505 \\
\hline 193.2 & 5.2902534 & -69.107657 & 74.397911 \\
\hline 193.3 & 5.3459129 & -69.22787 & 74.573783 \\
\hline 193.4 & 5.2884753 & -69.174047 & 74.462523 \\
\hline 193.5 & 5.3467558 & -69.337149 & 74.683905 \\
\hline 193.6 & 5.3465208 & -69.183785 & 74.530306 \\
\hline 193.7 & 5.3465215 & -68.840487 & 74.187009 \\
\hline 193.8 & 5.2880438 & -72.050712 & 77.338756 \\
\hline
\end{tabular}

(a) Frequency domain

\begin{tabular}{|l|l|l|l|}
\hline Wavelength $(\mathrm{nm})$ & Signal Power $(\mathrm{dBm})$ & Noise Power $(\mathrm{dBm})$ & OSNR (dB) \\
\hline 1552.5244 & 5.3460662 & -72.812439 & 78.158505 \\
\hline 1551.7208 & 5.2902534 & -69.107657 & 74.397911 \\
\hline 1550.918 & 5.3459129 & -69.22787 & 74.573783 \\
\hline 1550.1161 & 5.2884753 & -69.174047 & 74.462523 \\
\hline 1549.315 & 5.3467558 & -69.337149 & 74.683905 \\
\hline 1548.5148 & 5.3465208 & -69.183785 & 74.530306 \\
\hline 1547.7153 & 5.3465215 & -68.840487 & 74.187009 \\
\hline 1546.9167 & 5.2880438 & -72.050712 & 77.338756 \\
\hline
\end{tabular}

(b) In wavelength

Figure 4: reading from WDM analyzer corresponding to figure 3 


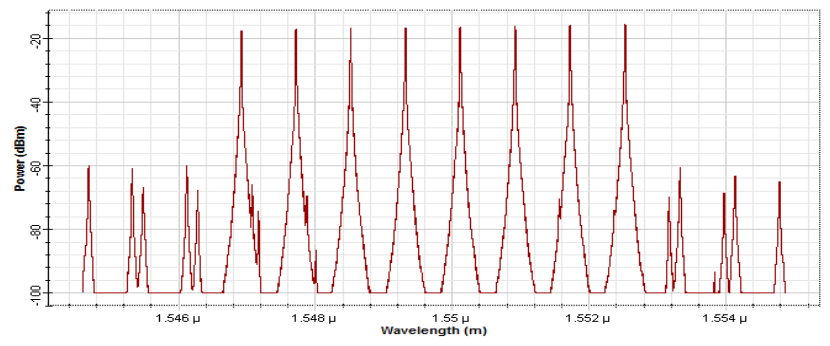

Figure 5: Reading from WDM spectrum analyzer at Demux input (shows attenuation and side bands)

comparing figure $3(\mathrm{~b})$ with figure 5 , It is clear that the signal has been attenuated down along the cable, thus a noticeable dispersion shown by some side bands but which is still too low (below $-60 \mathrm{~dB}$ ), to be picked by the receiver sensitivity used $(-18 \mathrm{dBm}$ improved to $-21 \mathrm{dBm}$ by $3 \mathrm{~dB}$ pre-amp gain ), in table 4 .

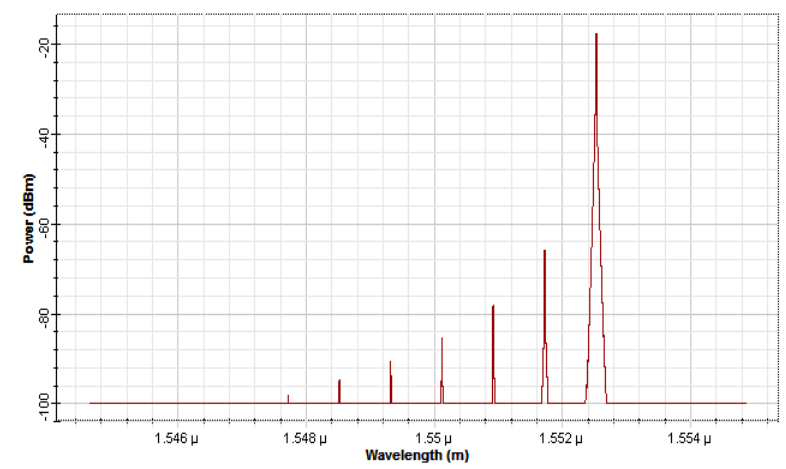

(a) Signal at the receiver

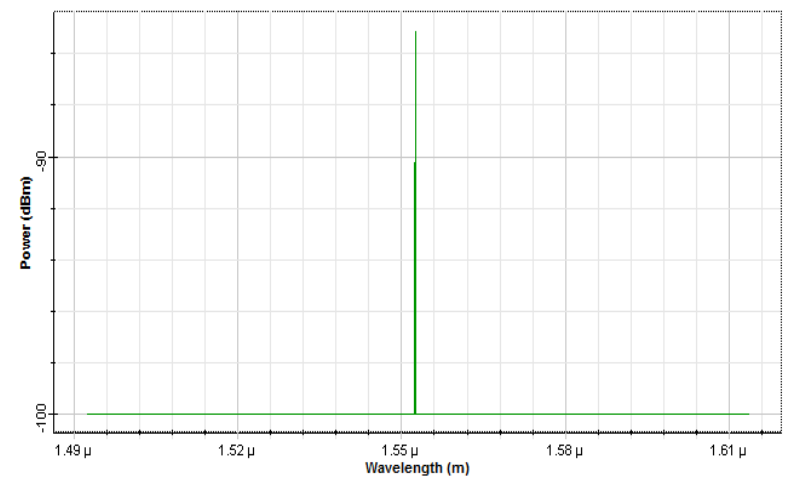

(b) Noise at the receiver

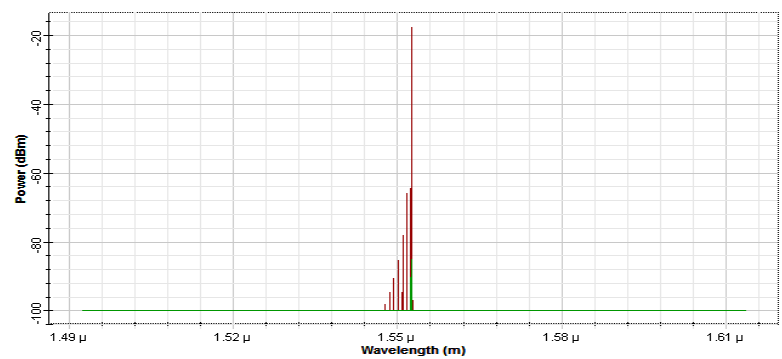

Figure 6: Reading from optical spectrum analyzer (a) merging with (b) for comparison

\subsection{Results analysis}

Network and Equipment Manufacturers (NEM), Service Level Agreements (SLAs) and Quality of Service (QoS) Agreements rely mostly on BER test [23]. However, companies complain that low BER of $10^{-9}$ for ITU-T recommendations and $10^{-12}$ for business transactions, BER test may take time of about 24 to 72 hours to get reliable statistical results depending on the data rates and Test method hence delaying deployment of new equipments. On the other hand NEM installers have found Q-factor to be quick even though sometimes is not efficient [23]. Fortunately, Optisystem 8.0 displays BER, Q-factor and eye diagram patterns, thus ideal for such quick link designs and simulations before deployment of resources. Figure 7 shows an example of the Eye diagram at a half of the cable length of this design with BER of 0 and Q-factor of 105.03 amplitude units (a.u).

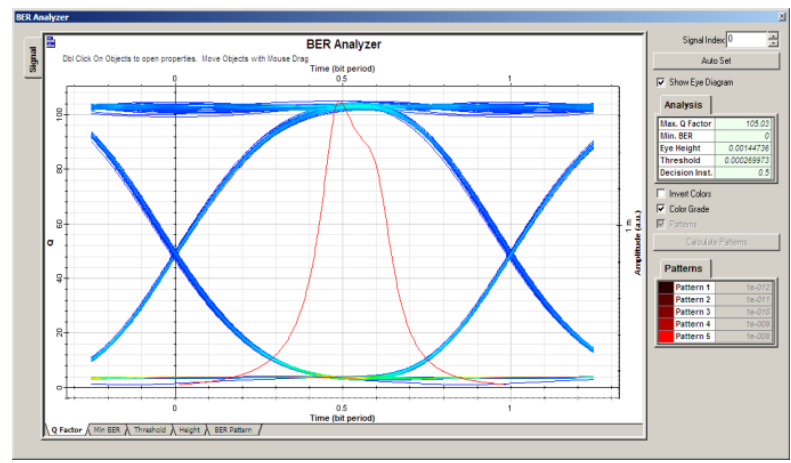

Figure 7: BER analyzer at a half link length $(50 \mathrm{~km})$

\subsubsection{BER and Q-factor Relationship}

The Q-factor in communication performance analysis signifies quality of the SNR in the "eye" of a digital signal [23].BER indicates the probability of an error occurring in a digital system such that a ' 0 ' may be interpreted as ' 1 ' and vice versa. With reference to figure 9, the two performance parameters are related by equation (13) given that the probabilities of ' 1 ' and ' 0 ' errors are equal.

$\mathrm{BER}=\frac{\mathrm{e}^{-\mathrm{q}^{2} / 2}}{\mathrm{Q} \sqrt{2 \pi}}$, where, $\mathrm{Q}=\frac{\left|\mu_{1}-\mu_{0}\right|}{\sigma_{1}+\sigma_{0}}$

In equation $13, \mu, \sigma$ are average and standard deviation at levels 1 and 0 respectively [22]. From BER estimation, it can be calculated that for BER of $10^{-9}$ or better, Q must be at least 6 amplitude units (a.u). Therefore ' 6 a.u' value was the major quantitative factor to determine the safety margin reserved about the design point in figures 12,13 and 14 .

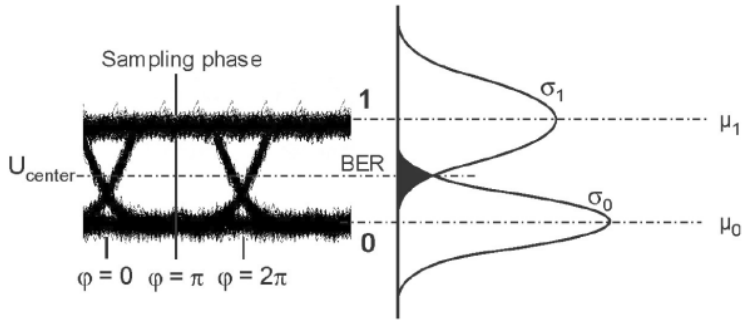

Figure 8: Sampling phase and distribution curves 
One disadvantage of using BER and Q-factor as performance analysis tools is that they give a quantitative judgement without justification. The better way is to use eye diagram contours analysis in addition to the two. This makes Optisystem 8.0 elegant and helpful to engineers in identifying the source of errors.

\subsubsection{Eye Diagram Analysis}

Eye diagram gives justification on a quantitative value obtained. In terms of excessive or less power, lower SNR, the degree of eye opening, degree of zero crossing distortion as well as dispersion and jitter effects. It is used as another major tool in analysing results. Performance analysis based on eye diagram analysis is characterised by for major indicators [16]:

Eye slope; a big slope leads to eye closure hence more sensitivity to timing errors and vice versa.

Eye opening; the wider the better because it gives high chance of sampling the signal with fidelity in case it is not sampled at the centre.

Crossover Width; the narrower the better because it indicates less jitter effects and vice versa.

Signal excursion; the smaller the better because it indicates less power wasted and vice versa.

\subsection{Simulation results and discussion}

Practically, in CWDM channels are not expected to have the same performance results. This is because channels are assigned different wavelengths and expected to be affected differently by associated phenomena along the fibre cable. In simulations and results analysis, all channels were tested and only the best and the worst channels are discussed in this paper. This means that all other channels performance lied within this range.

\subsubsection{Best Channel Performance Results}

Figure 9 Shows best channel performance of all 8 CWDM channels. Approximately only 5 chances out of $10^{97}$ bits sent for an error to occur $\left(\mathrm{BER}=5.44 * 10^{-9}\right)$ which corresponds to $\mathrm{Q}=20.9$.

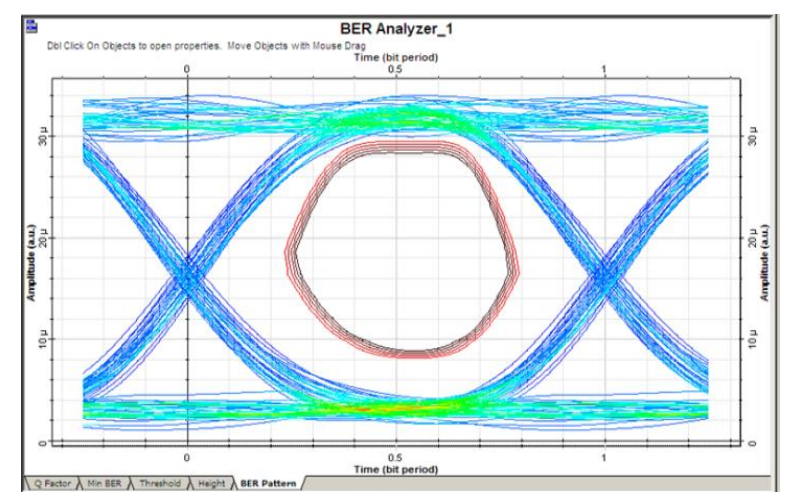

Figure 9: Eye diagram of the best channel performance at $100 \mathrm{Km}$ (full link length)

The results are by far satisfying ITU-T recommendations (BER of $10^{-9}$ or better). The Q-factor of 20.9 a.u is more than thrice the ' 6 a.u' which is considered to correspond to $10^{\text {' }}$ ${ }^{9}$ The eye height of $2.45 \times 10^{-5}$ a.u was about twice the threshold of $1.43 \times 10^{-5}$ a.u, below which the receiver starts misinterpreting the symbol. This gave a safety margin of about $1.02 \times 10^{-5}$ a.u before the signal at the receiver falls below the threshold. Decision instant was about 0.05 bit period away from the centre and all five patterns accommodated with in the eye opening (figure 15e). This is also another indicator of a good optical communication channel. The figure shows no recursion indicating that no wasted power.

\subsubsection{Worst Channel Performance Results}

Figure 11 depicts the worst channel performance in all 8 WDM channels. The minimum BER result was about $8.9 \times 10^{-9}$ at a maximum Q-factor of about 8.23. The rest of results discussions are based on this channel performance.

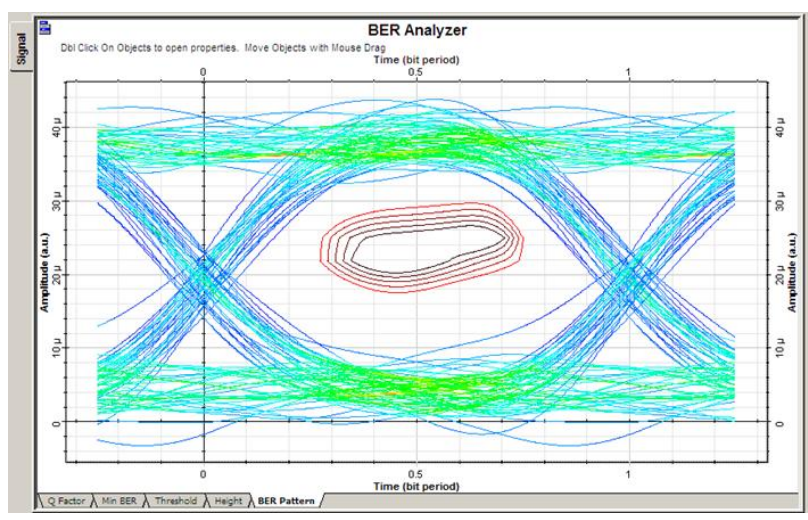

Figure 10: Eye diagram of worst channel performance

\subsubsection{Design and Performance parameters}

\section{Variation}

It would be a practice for a designer to demonstrate the safety margin region in which the system can operate before annoying errors occur with reference to the design point. In this section, independent parameters (design parameters) were varied and dependent parameters (performance) recorded. After variation with reference to the worst channel, graphs are plotted in figures, 11, 12 and 13 show the variation and the safety margin regions.

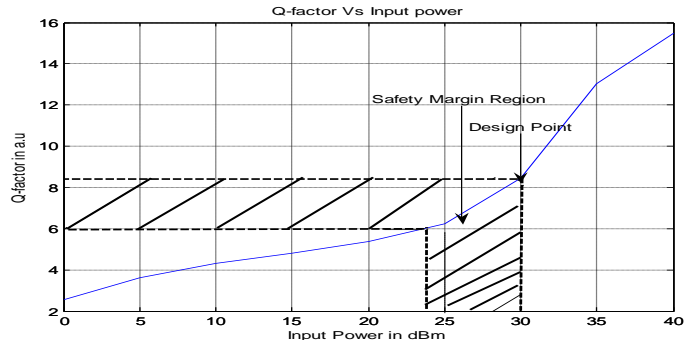

Figure 11: Q-factor versus input power

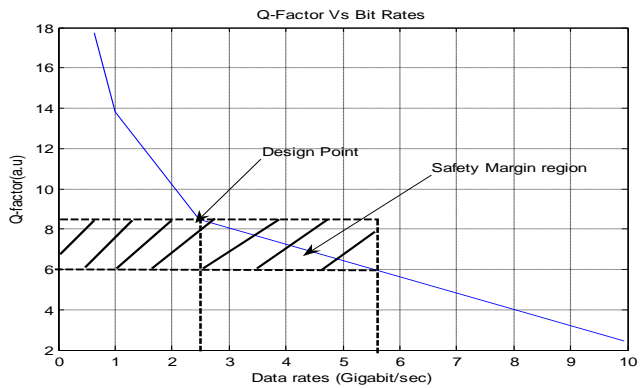

Figure 12: Q-factor versus input data rate 


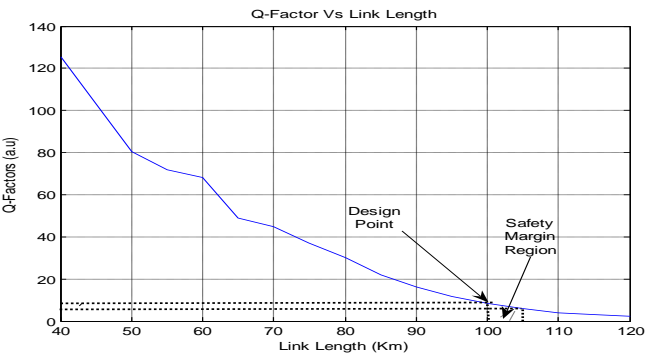

Figure 13: $Q$-factor versus link length

The design link length between onshore stations to subsea node was $100 \mathrm{~km}$. Simulation at this link resulted into Q-factor of about 8.23. Increasing the link increased attenuation hence performance deterioration. The safety margin showed only $5 \mathrm{Km}(105 \mathrm{Km}-100 \mathrm{Km})$ which justifies that attenuation is the major source of errors in fibre optic cable.

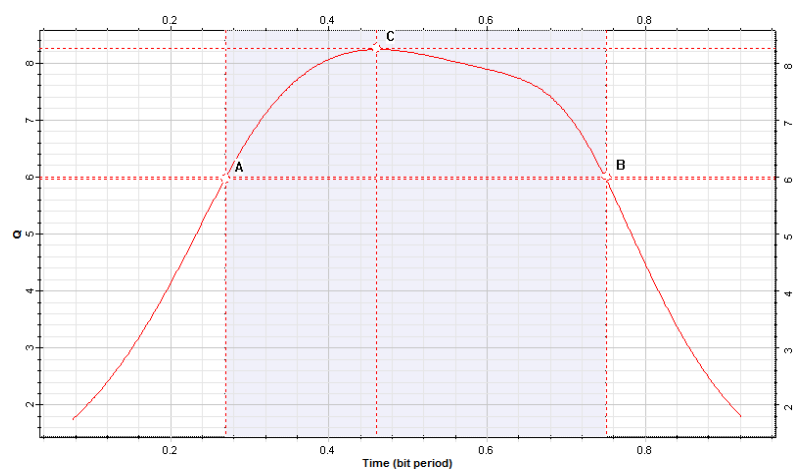

(a) Q-factor

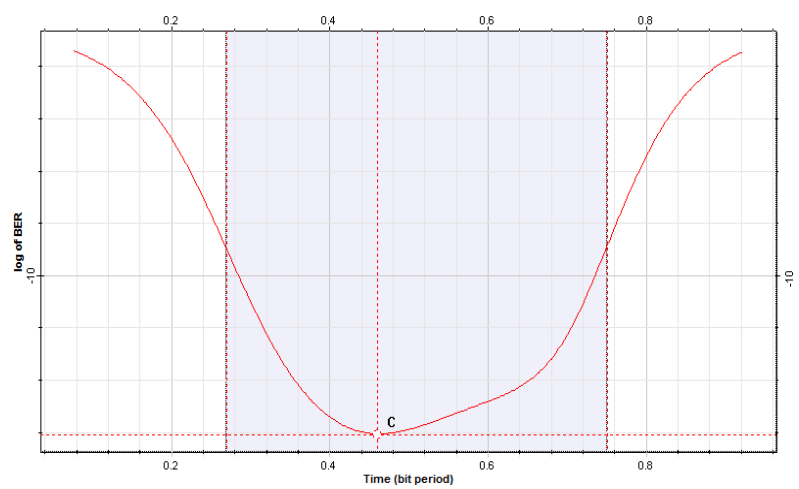

(b) Log of BER

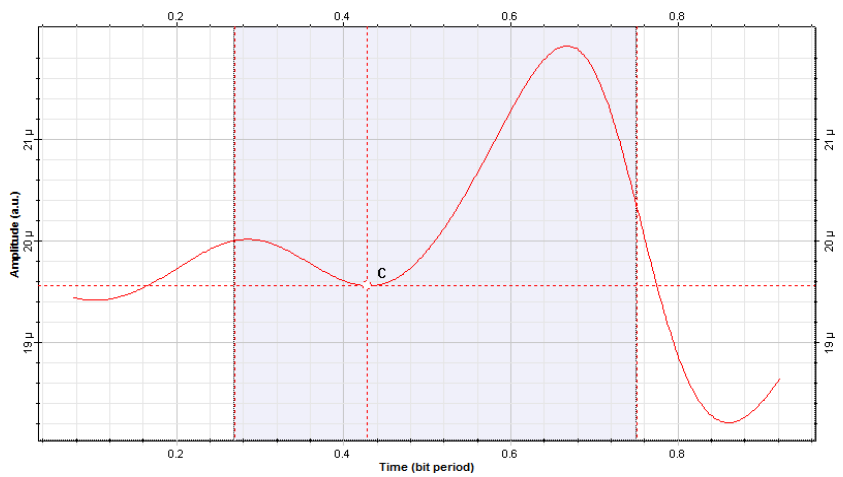

(c) Minimum threshold in acceptable time sampling.

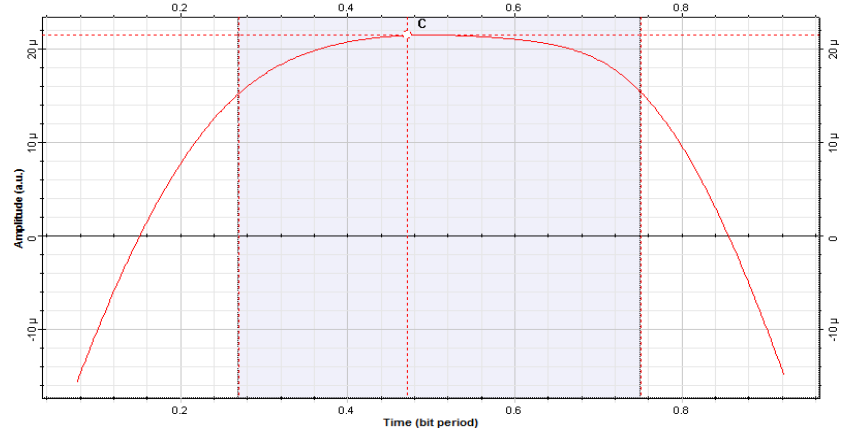

(d) Eye height

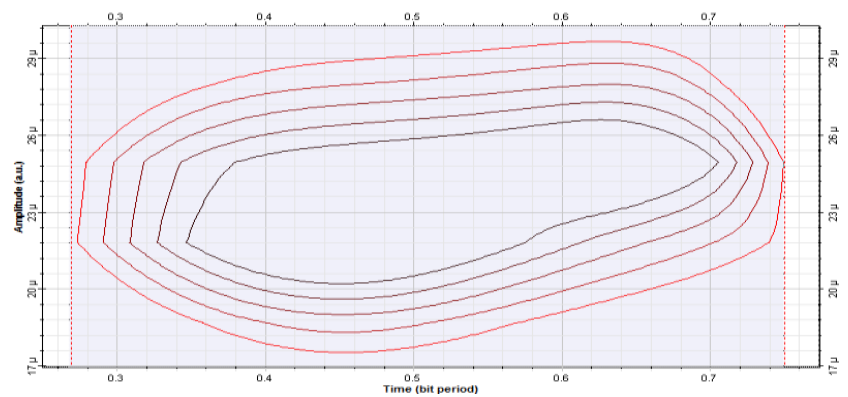

(e) All eye contours located in acceptable sampling time interval

Figure 14: Bit sampling time analysis at receiver

\section{CONCLUSION}

The aim of this paper was to review different sources of Fibre optic communication link design methodologies, use available component specifications, simulate and come up with informed decision Q-factor and BER in eye diagram for engineers prior to field deployment of resources.

In this paper, it was found that any fibre optic link with Qfactor less than 6 a.u is expected to have higher BER than ITU recommendation. From bit sampling analysis, it is clear that at a time sample where Q-factor is maximum, BER is always minimum and vice versa. For any good channel, all parameters involved should be operated in the shaded region of figure 14 and eye contours should remain in the same region.

Using a combination of good components with carefully selected bandwidth and power budget techniques, can leave an engineer with sufficient design margin to accommodate extra channels in DWDM scheme.

A combined analysis based on Q-factor and other eye diagrams features would give a clear and quick understanding of permanence for an optic fibre communication system to a designer before resource deployment.

\section{REFERENCES}

[1] R. N. Chiou, 2011. Bus FTTH Networks, Advanced Communication Technology (ICACT) International Conference.

[2] Chuan N. B, A Premad .A, Et al. 2010 Optical Power Budget and Cost Estimation for Intelligent Fiber-To-theHome ( $i$-FTTH), IEEE Conference Publications.

[3] Jaehyoung. P, Geun y. k, Et al, 2008. FTTH deployment status \& strategy in Korea , IEEE GLOBECOM

[4] Arsad. N., Mastang, B. B. 2007 .Impact of Fiber To The Home (FTTH), IET Optoelectron 
[5] Abdollahi S. R., Al-Raweshidy, Et al. 2010 , ALL photonic analogue to digital and digital to analogue conversion techniques, IEEE Conference Publications.

[6] Yifeng.S, Tiefeng .X, Et al. 2011 Characteristics Analysis of Millimeter Wave Signals Produced with Optical Carrier Suppression in ROF Systems, Electronics, Communications and Control (ICECC)

[7] Edward H. Sargent .2004 Towards CMOS-Compatible, Solution-Processed Quantum Dot Nanocrystal Optical Sources, , IEEE International Conference

[8] University of California Los Angles, 2004. fibre optic cable attenuation windows computer science department

[9] Jerzy .D and Anthony. G, 2013 Computationally Efficient Solution of Snell's Law of Refraction, IEEE Transactions on Ultrasonics

[10] C.H. Kwok, S.H. Lee, K.K. Chow and C. Lin Photonic crystal fibre based all-optical modulation format conversions between NRZ and RZ with hybrid clock recovery from a PRZ signal

[11] Thomas F. D, Steven M. S. 2011, Continuous Phase Modulation for Fiber-Optic Links, journal of light wave technology.

[12] Neville Hazell, 2006 Technological Infrastructure for Subsea Observatories Alcatel-Lucent Submarine Networks

[13] Perry, J., W. 2000. The future of fiber optics in the offshore oil Industry (A review of the subsea applications of optical fiber). North Williamson

[14] Perry, W., 2001. Optical fiber and Connectors: Optical and future subsea. Undersea technology, Florida.

[15] Butler R.A., 2009. Optical fiber and Radio communications lectures. School of Engineering, Robert Gordon University.
[16] Charan, L., 2002. Tutorial 15-How to interpret an eye diagram.

[17] Goff D.R., 2002. Fiber optic reference guide. $3^{\text {rd }}$ Ed. Amsterdam: Focal press.

[18] David, B and Edwin, W., 2003. Practical fiber optics. Oxford, Newnes.

[19] PERRY, J., W. 2000. The future of fiber optics in the offshore oil Industry (A review of the subsea applications of optical fiber). North Williamson

[20] Howard. P, Perry. W and Gary. C, 2006. Subsea to shore -challenges and solutions for subsea connections. Rio de Janeiro, France.

[21] Schlumberger, 2004. Subsea production assurance. Houston, USA. White paper

[22] KEITH, W., 2003. Q-factor a wrong answer for service providers and NEMs. Santa Clara, USA.

[23] Guy.F, 2005. Bridging the Gap between BER and Eye Diagram-A BER Contour, White paper Tutorial. San Francisco, USA.

[24] Ajoy.G and Thyagarajan, K. Introduction to fiber optics. 1998. Cambridge: University press.

[25] Optical Communication System Design. 2013 Video tutorials

[26] Mário R. G. And Adolfo V. T. , 2008. Impact of the Signal and Nonlinearity Extinction Ratios on the Design of Nonideal 2R All-Optical Regenerators, journal of light wave technology

Muhammad. I, Hamdan.A, Mohammed, 2013, Design and Simulation of Dispersion Compensated DWDM System, International Journal of Computer Applications (0975 - 8887) Volume 69- No.10, May 2013 